\title{
ÁNGELES EZAMA GIL, Las musas suben a la tribuna. Visibilidad y autoridad de las mujeres en el Ateneo de Madrid (1882-1939), Genueve Ediciones, Logroño [etc.], 2018.
}

Ser mujer, culta, liberal, comprometida con el entorno, amante de la literatura y de las artes y, además, parte activa de una institución clave de la cultura española, hubiera resultado toda una quimera si no se hubieran dado una serie de condiciones que Ángeles Ezama Gil recoge en su libro Las musas suben a la tribuna, visibilidad y autoridad de las mujeres en el Ateneo de Madrid (18821939).

Surgido tras las turbulencias políticas y sociales de la invasión napoleónica, el Ateneo dio visibilidad a todas esas mujeres que tuvieron algo que decir en un período político y social controvertido. El texto repasa su recorrido, primero como invitadas, después como socias, y más tarde como participantes activas en las conferencias y veladas, o como miembros de la junta directiva de la institución.

Pero es el éxito de su contribución como oradoras, el eje narrativo de un libro que analiza la actividad de mujeres comprometidas con la sociedad y con la política como Clara Campoamor, de escritoras que hablan sobre el papel de la mujer española en el extranjero, como Sofía Casanova, o de aquellas que analizan los fundamentos de la pedagogía social, como María de Maeztu.

El texto destaca de manera especial el papel como conferenciantes de Emilia Pardo Bazán y Blanca de los Ríos. De la primera constata sus vastos conocimientos de oratoria, repasa la temática de sus conferencias, su trayectoria como escritora o el interés mediático que despertó su actividad en los periódicos. De la segunda, la difusión de su actividad como investigadora, a través de sus intervenciones en la tribuna, y su posterior publicación en folletos, y en las reseñas de los periódicos.

Es también destacable el interés de la autora por analizar el modo en que se introdujo el feminismo en el Ateneo: señala a Concepción Gimeno de Flaquer como la primera que se atrevió a abordarlo de manera directa y también cómo muchos otros siguieron su estela: políticos de renombre como Maura o Canalejas, periodistas y escritoras como María Domenech de Canyellas, que habló 
desde la tribuna de la recién constituida Federación sindical de obreras, Carmen Karr que disertó sobre la cultura femenina, o Isabel de Oyarzabal que informó a las asistentes de las deliberaciones y acuerdos adoptados en el congreso celebrado en Ginebra sobre el sufragio de la mujer. ${ }^{1}$ Se completa este recorrido con autores como Victoriano Lillo, que les dio visibilidad dentro y fuera de la institución en un momento clave para la historia del feminismo en nuestro país.

Una extensa participación femenina en la vida cultural del Ateneo que se extiende a las veladas musicales, las lecturas poéticas, las veladas dramáticas y las veladas homenaje a escritores, músicos y miembros destacados de la institución.

Son las veladas musicales uno de los primeros actos culturales que estuvieron abiertos a las mujeres, ya fuese como concertistas, cantantes o bailarinas. El texto destaca los conciertos a piano de María Luisa Guerra, la participación de artistas noveles o la falta de interés en España por los conciertos de cámara. Señala también el auge de los conciertos, la proliferación de los dúos y de los tríos musicales, y los conciertos de música popular.

La danza se incorpora de manera tardía, pero con notable éxito; la bailarina Tórtola Valencia disipará los recelos de los socios, ante el hecho de que fuera la primera vez que se introducía dicha disciplina en las actividades culturales del Ateneo. ${ }^{2}$ Las lecturas poéticas y las veladas dramáticas van de la mano: actrices de teatro como Luisa Martínez Casado o María Guerrero López participan en las veladas poéticas y también en las representaciones teatrales. Finalmente, las veladas homenaje que, si bien no contaron en un primer momento con la participación de las mujeres, verán, gracias a Emilia Pardo Bazán, al frente de la sección de literatura, un destacado seguimiento en la prensa de dicho periodo.

El libro ofrece, en definitiva, una manera especial y única de conocer la historia de la institución a través de las relevantes aportaciones de todas esas mujeres a la cultura española.

María Silas García Conde Investigadora agregada del Instituto de Estudios Riojanos silasgarciaconde@me.com

1. 25 junio de 1920.

2. 24 enero de 1913. 